\title{
Construction of School-based Mental Health Records System
}

\author{
Xinhua Zhang ${ }^{\mathrm{a}}$, Yifan Jia ${ }^{\mathrm{b}}$, Juanjuan Wang ${ }^{\mathrm{c}}$ \\ Research Institute of Adolescent and Child Mental Health Development, Guang Dong Academy of Human Resources, Guangzhou, \\ GuangDong, China
}

\begin{abstract}
With the extraordinary advancement of Chinese society, primary and secondary school students are currently facing increasingly serious mental health problems, and an effective and easy-to-use system needs to be constructed to promote students' mental health in school. Here, we present the school-based mental health records system, including testing and recording, detailed assessment, intervention and mental health training, based on psychological theories and empirical studies. Besides, techniques and theories of play therapy was adopted to construct this system. We also explore the operability and effectiveness of this system by testing it at a school in Guangzhou. In conclusion, it is a feasible way for schools in China constructing this system to solve students' mental health problems.
\end{abstract}

\section{Introduction}

In recent years, with the rapid development of China's market economy, great changes have taken place in our living environment. At the same time, people's psychological problems have become increasingly prominent. Reflected in the group of primary school students, most of them show difficulties in interpersonal communication, poor willpower, behavioral and emotional problems, and rigid parent-child relationship [1]. A survey of 16,472 primary and middle school students nationwide also found that students with moderate and severe psychological and behavioral problems in primary and middle school accounted for $20.6 \%$ and $17.1 \%$ respectively [2]. In addition, since January 1, 2016, the Chinese mainland has implemented a "universal two-child" policy, which allows all couples, regardless of urban and rural, regional and ethnic, to have two children. Since the policy was implemented, many families with one child have given birth to a second child in succession, making the number of "two-child families" in China soar. Because of sibling rivalry, children in these two-child families often face more challenges and are more likely to have behavioral and emotional problems than only child. For example, through the study of parental rearing methods, it is found that parents of two-child families tend to pay more attention to the second child, thus the first child is prone to jealousy, resistance, hostility and other emotions, which will cause many behavioral problems [3].

To sum up, children in China are facing more and more prominent mental health problems, and in response to this situation, the voice of social concern for children's mental health is also growing. As the main activity place for children, schools bear a great responsibility in the education of children's mental health quality. Therefore, it is particularly important to establish a perfect and effective school-based mental health records system to monitor and intervene students' mental health problems in advance.

This paper describes and evaluates the personal profile, family background, personality characteristics, mental health status and values of primary and middle school students, so as to establish the mental health records of primary and middle school students, which has a significant effect on the school's mental health education, prevention and intervention of students' psychological problems [4].

Professor Huang Xiting, from psychology college of Southwest University's, has put forward three sub systems of "China's primary and middle school students mental health service system", including the mental health education system to promote students' psychological health level, the psychological consulting service system to correct students' psychological health problems, and the psychological disease treatment and crisis intervention system of emergency prevention and treatment of students' psychological disease [5]. In addition, Xu Guobin also put forward the "college students' psychological crisis management system" on the basis of the basic characteristics of psychological crisis management, such as urgency, long-lasting, uncertainty, prevention and humanism. The system includes three subsystems: the student psychological crisis prevention system, the student psychological crisis early warning system and the student psychological crisis intervention system. Among them, "prevention", "early warning" and "intervention" respectively play a role in three stages of psychological crisis: prevention management before it happens, crisis warning when it is about to happen and emergency intervention after it

\footnotetext{
* Corresponding author: ${ }^{a} 914414462 @ q q . c o m,{ }^{b j y f 19970111 @ 163 . c o m, ~}{ }^{c 3286879511 @ q q . c o m ~}$
} 
happens [6].

Based on the above researchers' exploration of school mental health management, this paper proposes a school-based mental health records system, which includes four parts: testing and recording, detailed assessment, intervention and mental health training.

\subsection{Testing and recording}

Psychological Testing is a kind of evaluation tool that uses standardized process to observe and score the behaviors of the tested in a specific field. It is an objective and standard measurement of individual behavior samples, so as to provide information for identifying whether an individual has psychological or organic problems [7]. Since French psychologist A·Binet has compiled the world's first intelligence test scale -Binet-Simon scale in 1905, research on the measurement of psychological quality and ability began to rise and reached its peak in the 1940s. For decades, psychological measurement has been regarded as an effective tool to measure individual differences [8]. Related research also shows that the validity of using maturity scale to measure individual psychological characteristics is good, even close to the validity of some medical diagnostic tools (e.g., computed tomography), thus psychological measurement has been widely used in talents selection, soldiers psychological state evaluation, people's attitudes towards social events survey and other aspects [9].

In the school environment, it is necessary to understand students' actual mental health conditions for discovering and intervening their mental health problems as soon as possible. In the field of clinical psychology, counselors often realize the psychological health status of individual cases through psychological testing and psychological assessment. Input-output ratio is very important in choosing specific ways to understand students' mental health [9]. Detailed psychological assessment often takes a long time and consumes a lot of manpower and material resources, so there is no need to conduct in-depth psychological assessment for all students in ordinary schools.

Compared with psychological assessment, the standardized process and results of psychological testing make it easier to meet the needs of large samples, and the results of psychological testing can also provide data support for subsequent evaluation $[10,11]$. Therefore, it can be seen that using psychological assessment scale tools for primary school stage children to conduct general children's psychological survey in schools and kindergartens and establish children's mental health records, is conducive to the screening of children's mental health problems, which is operable and scientific as a universal preventive means.

In fact, some researchers have discussed the significance of using psychological scale tools to conduct general psychological testing in schools and establish mental health records to some extent. Some researchers have suggested that psychological screening should be carried out at the entrance stage of college students, and follow-up mental health data should be archived afterwards. According to the established mental health database, key attention and intervention should be paid to the individual cases with potential emotional and social problems, so as to achieve the goal of promoting the comprehensive development of college students' mental health [12].Other researchers also pointed out that it is extremely necessary to establish mental health records of students in school, which is conducive to improving the current situation of the frequent occurrence of mental health problems of Chinese students and imperfect coping mechanism [13].

However, the above researchers mainly emphasize the construction of mental health records of middle school students and college students, and no researchers have yet discussed the significance of the construction of children's mental health records while the individual's cognitive ability, social ability and other psychological abilities are rapidly developing in childhood and gradually become mature. Therefore, children's mental health records are of great significance for the benign development of individuals. In addition, the mental health database of children established through general mental health survey can also be used by researchers in psychology, pedagogy, social work and other fields, which is conducive to the development of children's psychological research. A mental health survey covering 2,240 high school students shows that the data provided by the mental health survey can help school psychological workers and teachers prevent the occurrence of students' mental health problems and provide guidance for intervention programs [14].

\subsection{Detailed assessment}

Unlike psychological testing, psychological assessment is a series of complex processes for assessing individual mental state. Its purpose is to assess the individual's current functional ability, help counselors to establish the impact on visitors, determine the direction of intervention, make diagnosis, adjust intervention programs in time, manage potential risks, and provide valuable feedback for visitors $[9,15]$. Therefore, in-depth and detailed psychological assessment is still a necessary link to timely warn the students who may have mental health problems and effectively intervene in students who already have mental health problems.

However, in the school environment, there are always some limitations in the in-depth evaluation of students. On the one hand, as mentioned above, in-depth assessment often requires a lot of labor and time costs. For example, at present, Wechsler intelligence test is often used in China to systematically assess children's intellectual development level, but this assessment method often requires the examiners to have received psychological evaluation training in research institutes or professional institutions, and have enough practical experience; for each visitor, a complete evaluation usually takes 1 to 2 hours [16]. On the other hand, Chinese parents tend to attach importance to their children's scores but ignore their children's mental health. At the same time, they are relatively conservative about 
mental health problems and often attribute their children's mental health problems to moral problems, so it is difficult for them to accept their children's psychological evaluation [17]. Therefore, in the case of a rushed psychological assessment of students in the school with no basis, it may lead to the emergence of conflicts between school and home.

In order to avoid possible problems caused by psychological assessment and maximize its role in coping with students' mental health problems, in the current "school-based mental health records system", we first screen out children who may have mental health problems through the results of the school-wide mental health survey. Some children are on the list of special concerns. After that, professional resident counselors conduct one-to-one in-depth assessment of the children in the "list", and combined with the results of psychological survey, the final detailed evaluation results are obtained.

\subsection{Intervention}

Psychological intervention, or psychological therapy, refers to a professional relationship established between a professionally trained therapist and the client, to eliminate, correct or prevent the behavioral, ideological or emotional problems the client is facing [18]. Since the introduction of humanistic care in Pinel Mental Hspital in France in 1793, psychological intervention has been gradually created. In 1895, Breuer and Freud published The Study of Hysteria, which was the first time to combine psychiatry with clinical psychology. The school of psychoanalysis gradually emerged, greatly promoting the development of psychological intervention. Since then, psychological intervention has made great progress, with the emergence of various psychological interventions such as psychological dynamics, visitor center therapy, cognitive behavioral therapy, play therapy and so on [19].

The use of various forms of psychological intervention to help visitors is more effective than unplanned or informal help in improving the psychological health of visitors [20]. A large number of empirical studies also support this view. A meta-analysis of 475 studies covering 25,000 cases found that the mental health status of those who received intervention was significantly better than those who did not receive psychological intervention [21]. In addition, a large-scale survey covering 7,000 respondents showed that psychological intervention improved the mental health status of most people, and the effect of psychological intervention alone was not significantly worse than that of combination of drugs and psychological intervention [22].

Psychological intervention in the school environment emerged in the 1930s, then gradually developed towards specialization and maturity, and achieved great results $[23,24]$. The National Institute for Health and Care Excellence in UK also recommends that many of the psychological problems of childhood (for example, anxiety and depression) should be addressed in the school environment $[25,26]$. A review of more than 20 studies on psychological intervention in schools has found that psychological intervention in school environment is conducive to improving students' anxiety and other problems [27]. A large number of other empirical studies also prove that psychological intervention in schools has a positive impact on students' mental health [28-30].

Therefore, it helps to improve the all the school's students' mental health level by combining the results of previous mental health survey and in-depth assessment to select students who need special attention (students with mental health problems) and provide them with timely intervention by professional clinical psychological workers or counseling psychologists in the school environment.

\subsection{Mental health training}

Whether in the field of medicine or clinical psychology, good prevention is often extremely important for individual cases. Previous researchers have concluded that the current prevention schemes for students' mental health problems in the school environment mainly include three categories: universal prevention (for all students of the school); selective prevention (for students who may have psychological problems based on certain risk factors); indicative prevention (for students who have initially shown symptoms of mental health problems, sometimes referred to as early intervention) [49]. It is not difficult to see that the combination of the three parts of the "mental health records system" mentioned above can achieve the effect of selective prevention and indicative prevention. Therefore, in order to achieve more comprehensive and perfect prevention, universal prevention means should also be considered.

Comprehensive mental health training for teachers, parents and students in schools is a universal preventive measure that can be considered. Setting up mental health courses for all students in the school is helpful for students to establish mental health awareness, improve mental quality and ability and perfect students' personality, so as to achieve the goal of preventing students from mental health problems throughout the school [23]. In addition, creating a positive, friendly and open school atmosphere, providing timely and sufficient support for students' emotional development, cultivating and establishing students' sense of belonging to the school, are conducive to the improvement of all students' academic performance and the reduction of risky behaviors [50]. Through the training of mental health knowledge for teachers and parents, awareness and skills are established so that they can create a harmonious and healthy school atmosphere and promote the mental health development of all students.

\subsection{The current study}

Although many researchers have pointed out that to establish a scientific and perfect mental health system for school students' mental health work is necessary, and 
many empirical studies have shown that psychological testing, psychological assessment and intervention in school and the counseling and mental health training of teachers, parents and students are conducive to students' psychological healthy development. However, in the process of literature review, it has not been found that researchers have systematically combined the above four parts to form a system, nor have they found any practical application of this system. Therefore, the purpose of the current study is to integrate and construct a complete and comprehensive school-based mental health records system, and introduce the application strategy of the system in schools with examples.

Obviously, both the above in-depth assessment and intervention counseling require specific psychological therapy as a support. In the current system, we are considering the theory and technology of play therapy.

Play therapy, in a mild, trusting and completely free environment, helps individuals, especially children, detect their own problems and tap their potential through the form of games, so as to achieve the treatment method of preventing and solving psychological crisis [31]. A large number of practices show that as an effective means of child psychotherapy, play therapy has a wide range of clinical indications and application prospects. It can be used for reference by teachers, parents, clinicians or other ideological workers of children and adolescents [32], which is not only for the children with psychological disorder but also for healthy children's psycho-health guidance. In addition, a meta-analysis of 94 studies involving the curative effect of play therapy found that the curative effect of play therapy on children was good and positive [33]. In the report, they pointed out that the curative effect of play therapy has the universality, which is regardless of game players' personality, age, sex, living environment and trust theories. No matter whether they formally accept play therapy in clinical treatment, the treatment can effectively cure or alleviate the symptoms of game participants. Empirical studies have shown that play therapy can solve or improve children's psychological behavioral situations such as hair pulling, keeping silent, violent and impulsive behaviors, emotional regulation ability, stress and anxiety problems, and reading ability [34-42].

The application of play therapy in school environment appeared in the 1960s. During this period, a large number of counseling educators encouraged the use of play therapy in school environment to meet the needs of most children, to help children prepare to learn knowledge from existing school curricula, and to enable teachers to help children adapt to school in advance, which make children voluntarily and actively participate in learning [43-48].

Therefore, in the current system, we assign counselors who have received professional play therapy training as resident counselors in primary schools and kindergartens to complete the in-depth assessment and intervention counseling in the mental health records system, so as to improve the mental health level of the whole school students.

\section{The establishment of school-based mental health records system}

The school mental health records system includes four parts: testing and recording, detailed assessment, intervention and mental health training. The process of building the system in the school is as follows: firstly, the psychological test scale suitable for students of different grades is used to conduct a survey in the whole school, then the school's mental health records are established and students who may have mental health problems are screened out according to each student's score to form a list of special concerns; secondly, professional psychological counselors for children are selected to enter the school, and professional psychological evaluation technology is applied to conduct in-depth one-to-one assessment of students on the list of special concerns, so as to comprehensively and objectively grasp the mental health status of these students and formulate follow-up intervention plans. After that, the resident psychological counselors will conduct regular one-to-one psychological counseling for the children on the special attention list in the psychological counseling room of the school according to the intervention program. In addition, the training of mental health related knowledge and skills for teachers, parents and students runs through the whole process. The basic framework of the mental health records system is shown in figure 1 . 


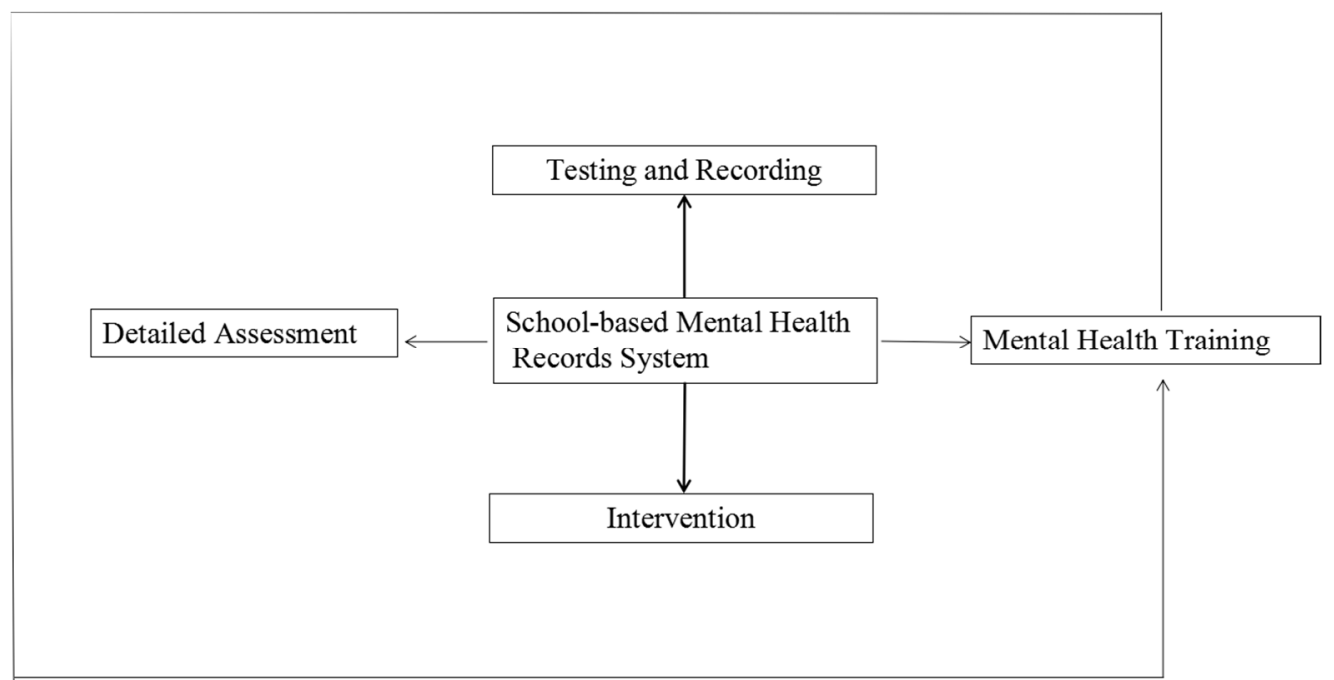

Figure 1 The basic framework of the mental health records system

further evaluation.

\subsection{Testing and recording}

To conduct the school-wide mental health survey, it needs to construct the scales needed for the survey. Here, we select the following relatively mature scales to help construct the scale set for the school-wide survey.

Language development screening scale for children aged 1 to 6: this scale is derived from Pocket Guide to Assessment in Speech-Language Pathology, which can be used to identify whether children of different age groups have language development delay and disability [51]. The original scale has different scales for $1 \sim 2$ years old, $2 \sim 2.5$, and $2.5 \sim 3$ years old, $3 \sim 4$ years old, $4 \sim 5$ years old, $5 \sim 6$ years old respectively, each scale including eight questions related to the language skills (for example, "can use 100 or above words"). Parents or teachers complete each question from "failing to master" to "mastering most of the time " 4 points according to the daily observation of the children. When the children in this age group score 1 or 2 in half or more of the questions, it is considered as a suspected language development delay and disorder, which requires further evaluation.

Intelligence development screening scale for children aged 1 to 6: this scale is derived from DSM-IV (Diagnostic and Statistical Manual of Mental Disorders: 4th Edition) and EDM (The Educator's Diagnostic Manual of Disabilities and Disorders), which is used to detect whether preschoolers have intelligence development delay $[52,53]$. The original scale has different scales to evaluate children aged 1 to 6 . Except for 10 questions for children aged 1 to 2 , the other scales include 12 questions related to children's intellectual performance (for example, "can complete a puzzle divided into 3 to 4 pieces"). Questions are scored from "failing to master" to "mastering most of the time " 4 points. All the questions are graded by parents and teachers according to the observation of children at daily times. When half or more of the questions on the corresponding scale of a child's age are " mastering sometimes" or " failing to master ", they are considered as a suspected intelligence development, which requires
Writing problem screening scale for children aged 2 to 6: this scale is designed based on the previous research on children's writing problem evaluation, and is used to identify whether there are problems in children's writing ability and fine motor ability $[54,55]$. A scale was used to measure children aged 2 to 6 ( 2 to 3 and 3 to 4 were one age group respectively, and so on). Each scale includes seven questions, which can be used to judge whether children can complete a fine operation (for example, " drawing lines in $1 \mathrm{~cm}$ curve tunnel "). Questions are scored from "failing to master" to "mastering most of the time " 4 points. Parents or teachers finish grading according to children's daily performance. When half or more of the questions on the corresponding scale of a child's age are " mastering sometimes" or " failing to master ", follow-up evaluation will be arranged.

Emotion and behavior problem screening scale for children aged 6 to 12: this scale is also derived from EDM, which is used to identify children with emotion and behavior problems [53]. The scale includes two subscales, which are used to evaluate children's emotional and behavioral problems respectively. Among them, the emotional problem subscale includes 8 questions, each of which is related to a child's emotional performance (for example, "emotional fluctuation"). The behavioral problems subscale consists of 10 questions, each of which is about a child's bad behavior (for example, "not following the teacher's instructions"). The questions in both sections range from "never" to "often" and are scored on a 4 points scale based on the child's daily performance. If a child has nine or more items rated as "sometimes" or "often" and behavioral and emotional performance lasts two months or more, the child needs further evaluation.

Intelligence development screening scale for children aged 6 to 12: this scale refers to DSM-IV and EDM [52, 53], and can be used to preliminarily identify whether children aged 6 to 12 have problems with intelligence development. The scale consists of 12 questions, which are about the possible manifestations of children with intellectual disabilities (for example, "compared with 
children at the same age, the child needs to spend more time reading Chinese and English characters"). The questions are scored on a 4 points scale ranging from "never" to "often," and the respondents completes the scale based on their observations of the children's performance. Further assessment is required if half or more of the items scored are "sometimes" or "often".

Learning method screening scale for children: this scale is selected from The Child Development Assessment Form published by Hong Kong Heep Hong Society in 2006 to identify the main learning strategies of children [56]. The scale has a total of 16 projects, each of which corresponds to a learn situation of a child (for example, "when reviewing the lessons"). Each question has a total of 3 options for the single choice, corresponding to visual learning strategies (such as, "taking notes, drawing key points"), auditory learning strategies (such as, "like to listen to music") and kinesthetic learning strategies (such as, " uncomfortable of sitting motionless"). The children will fill in according to their daily performance. According to the types of learning strategies that children choose most, children are divided into auditory learners, kinesthetic learners, visual-auditory learners, visual-kinesthetic learners and auditory-kinesthetic learners. The results of this scale are helpful for teachers and parents to design appropriate learning requirements and contents for children according to their preferred learning strategies.

Due to the specificity of children's development of cognition, emotion, behavior and so on at different ages, in order to reasonably combine the above scales to construct The Children's Psychological Assessment Scale, we eventually developed a total of 6 sets of standardized tests for primary school students in all grades according to the cognitive development theory of Piaget and the personality development stage theory of Eriksson's, combining with the characteristics of development of children at different ages. It is worth noting that since using only self-evaluation to evaluate individuals may cause deviation information such as social desirability bias, it is necessary to combine other evaluation forms to obtain more comprehensive and complete information of individuals [23]. Therefore, the standardized test scale currently constructed is completed by students, parents and teachers in order to obtain more objective and comprehensive individual information. See table 1 for the specific construction methods of standardized scales used for testing and recording in this system. In fact, the above series of scales have been granted national copyright patent in 2016. The specific name and patent registration number of scale are shown in table 2 .

After the construction of psychological survey scale, a series of scales can be used to start a comprehensive psychological testing in school. In order to facilitate the implementation of the survey, psychological knowledge popularization lectures for teachers, parents and students of the whole school can be conducted before the formal testing to explain the significance and operation process of the survey. In order to improve the efficiency of the survey, the data collection can be completed in the form of computer test in class unit, and the test system can automatically input the data to the database to establish the students' mental health records.

Table 1 The standardized psychological test scale for primary school children

\begin{tabular}{|c|c|c|c|}
\hline & Self-rating & Parent-rating & Teacher-rating \\
\hline $\begin{array}{l}\text { First } \\
\text { Grade }\end{array}$ & N/A & $\begin{array}{l}\text { Emotion and behavior problem screening scale for } \\
\text { children aged } 6 \text { to } 12 \\
\text { Intelligence development screening scale for } \\
\text { children aged } 6 \text { to } 12\end{array}$ & $\begin{array}{l}\text { Emotion and behavior problem } \\
\text { screening scale for children aged } 6 \text { to } \\
12\end{array}$ \\
\hline $\begin{array}{l}\text { Second } \\
\text { Grade }\end{array}$ & N/A & $\begin{array}{c}\text { Emotion and behavior problem screening scale for } \\
\text { children aged } 6 \text { to } 12 \\
\text { Parenting style screening scale }\end{array}$ & $\begin{array}{l}\text { Emotion and behavior problem } \\
\text { screening scale for children aged } 6 \text { to } \\
12\end{array}$ \\
\hline $\begin{array}{l}\text { Third } \\
\text { Grade }\end{array}$ & $\begin{array}{c}\text { Emotion and behavior problem } \\
\text { screening scale for children aged } 6 \text { to } \\
12 \\
\text { Learning method screening scale for } \\
\text { children }\end{array}$ & $\begin{array}{l}\text { Emotion and behavior problem screening scale for } \\
\text { children aged } 6 \text { to } 12\end{array}$ & $\begin{array}{c}\text { Emotion and behavior problem } \\
\text { screening scale for children aged } 6 \text { to } \\
12\end{array}$ \\
\hline $\begin{array}{l}\text { Forth } \\
\text { Grade }\end{array}$ & $\begin{array}{l}\text { Emotion and behavior problem } \\
\text { screening scale for children aged } 6 \text { to } \\
\qquad 12 \\
\text { Children self-cognition scale }\end{array}$ & $\begin{array}{l}\text { Emotion and behavior problem screening scale for } \\
\text { children aged } 6 \text { to } 12 \\
\text { Family values observation scale }\end{array}$ & $\begin{array}{l}\text { Emotion and behavior problem } \\
\text { screening scale for children aged } 6 \text { to } \\
12\end{array}$ \\
\hline $\begin{array}{l}\text { Fifth } \\
\text { Grade }\end{array}$ & $\begin{array}{c}\text { Emotion and behavior problem } \\
\text { screening scale for children aged } 6 \text { to } \\
12\end{array}$ & $\begin{array}{l}\text { Emotion and behavior problem screening scale for } \\
\text { children aged } 6 \text { to } 12\end{array}$ & $\begin{array}{c}\text { Emotion and behavior problem } \\
\text { screening scale for children aged } 6 \text { to } \\
12\end{array}$ \\
\hline $\begin{array}{l}\text { Sixth } \\
\text { Grade }\end{array}$ & $\begin{array}{c}\text { Emotion and behavior problem } \\
\text { screening scale for children aged } 6 \text { to } \\
12 \\
\text { Connor-davidson resilience scale }\end{array}$ & $\begin{array}{l}\text { Emotion and behavior problem screening scale for } \\
\text { children aged } 6 \text { to } 12\end{array}$ & $\begin{array}{l}\text { Emotion and behavior problem } \\
\text { screening scale for children aged } 6 \text { to } \\
12\end{array}$ \\
\hline
\end{tabular}


Table 2 The national copyright patent registration number of serial scales used in the survey of children's mental health records system

\begin{tabular}{ll}
\hline Scales & Copyright Number \\
\hline Overall development series scales for children & Yuezuo-2016-A-00000839 \\
Learning ability series scales for children & Yuezuo-2016-A-00000837 \\
$\begin{array}{l}\text { Emotion, behavior, cognition and parenting style series } \\
\text { scales for children }\end{array}$ & Yuezuo-2016-A-00000838 \\
Physical development series scales for children & Yuezuo-2016-A-00000840 \\
\hline
\end{tabular}

\subsection{Detailed assessment}

After completing the school-wide psychological survey and establishing students' mental health records, teachers of the school select $2 \%$ of students into the "special attention list" according to the results of the survey and students' daily performance. After that, the teacher in charge of the class fills in the "student registration form" and communicates with the professional resident psychological counselor to make the consultant understand the basic information and situation of the students. The assessment time is arranged by the school, and each student's assessment is completed in the psychological counseling game room of the school, and the assessment time is about 45 minutes.

After the evaluation is completed, the resident counselor writes the evaluation report and transfers it to the student's teacher in charge of the class or parents.

In the current system, some assessment techniques for children in play therapy are adopted, including "evaluation of children's mental development", "internal motivation" and "family animal graph". These assessment techniques are rooted in painting test, projection metaphor and other theories, and can be used to evaluate children's mental health in three aspects: personal ability, psychological status and social relationship, and family interaction mode. Through the practical verification of many game psychotherapists, these methods are suitable for the use of the school environment with the advantages of scientific and effective, easy operation, simple props requirements.

\subsection{Intervention}

After an in-depth assessment of the children on the list of special concerns, it will be followed by the communication with the teacher in charge of the class to identify the students for follow-up intervention and counseling. Short-term intervention is generally carried out for students with special circumstances (such as bereavement, divorce of parents, major diseases and major traumatic events). The specific intervention method is that the resident counselor carries out 45 minutes of psychological intervention with play therapy technology in the psychological counseling game room of the school at a fixed time every week. The course of treatment depends on the specific assessment results of the students.

\subsection{Mental health training}

Different from the first three parts, the whole training part runs through the whole mental health records system and targets at students, teachers and parents. Among them, at the student level, training mainly includes "group guidance" and "class integration". The former is guided by resident counselors to conduct group counseling for students with behavioral or social problems to help them integrate into the group. The latter is achieved through self-study classes, physical education classes, activity classes and so on, under the guidance of the resident counselors, to carry out the construction activities of each class, enhance the students' group consciousness and cohesion, and promote the interaction, communication and harmony of the class.

Since teachers are the most important part of the school environment, it is more important for teachers' mental health training. At the micro level, the resident counselors can follow up the guidance of students through interviews with teachers, provide feedback report and put forward specific suggestions to teachers. At the macro level, through lectures, group counseling and other forms, teachers are assisted in understanding how to carry out the prevention, counseling and follow-up work of children's mental health and understand the uniqueness of students, so as to make teaching development meet the needs of different students and other professional psychological health education technology.

The training for parents is mainly through discussing the future educational arrangements of students with the parents of students on the special attention list and conducting lectures for parents to help them understand children's mental health development, master more methods of disciplining children, and learn to deal with the problems encountered in the growth of children.

\section{Examples explain}

In order to better present the construction mode of mental health records system, this paper takes $\mathrm{C}$ school in Guangzhou, which has been building this system for two years, as an example to illustrate the specific construction mode of this system and explore its effectiveness and operability. 


\subsection{School and resident counselor}

C school is a primary school in Guangzhou. Currently, there are 32 classes in six grades and about 1300 students in $\mathrm{C}$ school. There are about 80 staff members in the school, with a teacher-student ratio of about 1:16. The school set up an indoor space of about $40 \mathrm{~m}^{2}$ as a play therapy consulting room. The resident counselors assigned to the school have received nearly 300 hours of practice and supervision of game therapy cases. They are fixed in the school's play therapy room every Wednesday all day to provide psychological assessment and intervention services for school students.

\subsection{The construction of mental health records system in the school}

In September 2016, a standardized series of assessment scales was used to conduct a survey of all students in the school. According to the survey results, the number of children who need special concerns screened out by the school accounted for $12.7 \%$ of the total number of students in the school. After that, the resident psychological counselor and the teacher in charge of the class jointly agreed to select the students in the special concerns list for further evaluation and intervention counseling. In order to explain the construction of the mental health records system in the school more specifically, the background, evaluation results and intervention methods of some cases are presented here. In order to comply with the confidentiality agreement signed with the parent of the case, the names shown below are pseudonyms.

Xiaoxi, an 11-year-old fifth-grade boy who has entered the special attention list, was advised by the teacher to conduct an in-depth assessment because he could not listen to the teacher carefully and complete his homework, especially the math homework. However, this student likes reading the extra-curricular book about history and the composition can be completed. The counselor evaluated the child using child-centered play therapy and mental development assessment techniques, and then arranged intervention plans based on the assessment results. One-to-one counseling lasted from the first semester of grade five to the second semester of grade six, and 45-minute one-to-one game therapy sessions were conducted for 21 times, including one meeting with parents and eight interviews with teachers. After the completion of the intervention plan, according to the feedback from teachers, parents and counselors, this student's ability in emotional control, coordination degree, interpersonal communication and other aspects after the guidance has been significantly improved, his classroom performance and homework completion have also been greatly improved, and he is able to accept certain setbacks and changes.

Xiaoxi (Grade one), another student who entered the special attention list, has encountered great difficulties in his studies since he entered the school. He showed poor concentration in class and thus poor academic performance. In his life, Xiaoxi is not organized about his belongings and often appears the question of forgetful In terms of interpersonal communication, although Xiaoxi has strong initiative, he often has conflicts with his classmates and finds it difficult to solve them by himself. In addition, Xiaoxi's mood fluctuates greatly and is difficult to control, and he often makes loud noises on all occasions. After the evaluation of Xiaoxi, the resident psychological counselor conducted a total of 14 hours of intervention counseling in three semesters. After the completion of the intervention plan, Xiaoxi has significantly improved his concentration, awareness of rules, emotional management and other aspects. There are fewer distractions in class, more harmonious interpersonal relationships, and he has been able to keep his temper.

Similarly, Xiaoxuan, a first-grade boy, performed poorly in class and would talk casually or even leave the classroom and walk around the campus. He has poor emotional management ability, is easy to be excited, and has self-injurious behaviors such as bumping head and slapping his hands; he is difficult to follow and execute instructions. Since then, based on the assessment results, the resident psychological counselor has provided psychological counseling services for him for two semesters, including 21 times 45 -minute one-to-one game therapy sessions, 11times parent meetings and 10 times teacher interviews. After the completion of the intervention plan, the instructor gave the feedback that Xiaoxuan has a full sense of security, good connection with the reality, can express his inner feelings reasonably; teachers and parents reported improved academic and social performance.

In the 2016-2017 school year, a total of 10 lectures on mental health knowledge for teachers and parents were conducted in primary school $\mathrm{C}$ under the supervision of professional game therapists, once a month on average. Topics include how to help children build self-knowledge, how to better understand children, how to help children improve interpersonal relationships, etc., helping teachers and parents create a good atmosphere for the mental health development of school students.

After one-year implementation of the mental health records system in primary school $\mathrm{C}$, according to the feedback from teachers and parents, the system has strong operability and is effective in improving the overall mental quality and mental health of students. The school decided to use the mental health records system to serve students' mental health for a long time.

\section{Conclusion}

Mental health records system includes "testing and recording, detailed assessment, intervention and mental health training " four major parts. With scientific psychological assessment tools, combined with modern means of science and technology, through the intelligent online assessment platform, conducting tracking evaluation for children aged 3 to 12 , establishing child mental health data, the system provides a comprehensive, objective and scientific reference for the growth of the students, the teaching methods teachers and the school 
policy. Then, based on the testing results, children are selected to join the list of special concerns, and in-depth one-to-one assessment will be provided to these children, so as to have a more comprehensive understanding of the current psychological status of children and its causes, and provide teachers and parents with more detailed assessment reports and recommendations. Based on the assessment results and communication with parents and teachers, some children in the "list" will have one-to-one regular intervention counseling to improve the mental health of these students and promote their physical and mental health development. Providing related seminars and training regularly for teachers, parents and students with children's mental health, through various forms to help improve the students' psychological quality, can help teachers and parents understand the child's psychological development characteristics at each age stage, master more professional way of upbringing and education, thus create healthier growth environment for the development of the child. The whole system, covering the three parts of "prevention -- early warning -intervention" in education of student mental health, is a set of relatively scientific, complete and effective student mental health records system, which provides a feasible solution for the increasingly severe current situation of mental health of primary and secondary school students in China, and has far-reaching practical significance.

\section{Acknowledgement}

We gratefully acknowledge the support provided by Ms. Kong hong and Ms. Zhou Xuelian for providing important case data for this paper, Ms.Yin Jieru for providing data for this article and Ms. Yuan Qinglian for her valuable suggestions on the revision of this paper.

\section{References}

1. S. Meng, An investigation of the mental health of Chinese primary school students, Shang Research on Education, vol. 8, pp. 42-45, 2010.

2. Q. Liao, Epidemiological research advancement of mental health problems in primary and junior high school students, Health Medicine Research and Practice, vol. 4, pp. 67-70, 2007.

3. B. Chen and Z. Shi, Parenting in families with two children, Advances in Psychological Science, vol. 25, pp. 1172-1181, 2017.

4. M. Li, Exploration on construction of mental health records for primary and secondary school students Theory Research, vol. 15, pp. 220-221, 2011.

5. Q. Liao and X. Huang, The construction of the mental health service system pattern for primary and middle school students, Psychological Science, vol. 32, pp. 274-277, 2009.

6. G. Xu, Psychological Education and Counseling for College Students, Science Press, 2012.

7. AERA, APA and NCME, Standards for educational and psychological Testing, American Psychological
Association, 2014.

8. L. Liu, Review of Chinese and other countries' psychological quality assessment, Journal of Chengdu Institute of Public Administration, vol. 3, pp. 91-96, 2012.

9. G. J. Meyer, S. E. Finn, L. D. Eyde, G. G. Kay, K. L. Moreland, R. R. Dies, ... and G. M. Reed, Psychological testing and psychological assessment: A review of evidence and issues, American psychologist, vol. 56, pp. 128, 2001.

10. W. J. Camara, J. S. Nathan and A. E. Puente, Psychological test usage: implications in professional psychology, Professional Psychology Research \& Practice, vol. 31, pp. 141-154, 2000.

11. M. P. Maloney and M. P. Ward, Psychological assessment: A conceptual approach, 1976.

12. X. Zhang, College students' mental health, the value of the database established connotation and path, Journal of Anhui Health Vocational \& Technical College, vol. 16, pp. 7-8, 2017.

13. X. Fan, The necessity and problems of construction of students' psychological records Lantai World, vol. 15, pp. 38-39, 2016.

14. E. Dowdy, M. Furlong, T. C. Raines, B. Bovery, B. Kauffman, R. W. Kamphaus, B. V. Dever, M. Price and J. Murdock, Enhancing school-based mental health services with a preventive and promotive approach to universal screening for complete mental health, Journal of Educational and Psychological Consultation, vol. 25, pp. 178-197, 2015.

15. M. P. Maloney and M. P. Ward, Psychological assessment: a conceptual approach, American Journal of Psychiatry, vol. 134, pp. 471-471, 1977.

16. P. Wang, Child Development Assessment and Counseling, Psychological Publishing, 2011.

17. Y. Lai, Study on perceptions towards 'mental health' among parents of middle school students, 2016.

18. L. R. Wolberg, The technique of psychotherapy New York: Grune and Stratton, 1967.

19. E. J. Phares, Clinical Psychology: Concepts, Methods, \& Profession, Thomson Brooks/Cole Publishing Co, 1992.

20. J. D. Frank, The present status of outcome studies, Journal of Consulting and Clinical Psychology, vol. 47, pp. 316-319, 1979.

21. M. L. Smith, G. V. Glass and T. I. Miller, The benefits of psychotherapy, Baltimore: Johns Hopkins University Press, 1980.

22. M. E. Seligman, The effectiveness of psychotherapy: the consumer reports study, American Psychologist, vol. 50, pp. 965, 1995.

23. G. Yu and R. Hou, On school mental health service and its system construction, Educational Research, vol. 36, pp. 125-132, 2015.

24. S. Sun, Review of the history and current situation of the development of school psychological 
counseling, The Modern Education Journal vol. 5, pp. 36-40, 1994.

25. NICE, Depression in children and young people: NICE guideline, 2005.

26. NICE, Social anxiety disorder: NICE guideline, 2013.

27. A. L. Neil and H. Christensen, Efficacy and effectiveness of school-based prevention and early intervention programs for anxiety, Clinical Psychology Review, vol. 29, pp. 208-215, 2009.

28. G. W. Albee and T. P. Gullotta, Primary prevention works, Thousand Oaks, CA: Sage, 1997.

29. T. M. Anglin, K. E. Naylor and D. W. Kaplan, Comprehensive, school-based health care: high school student's use of medical, mental health, and substance abuse services, Pediatrics, vol. 97, pp. 318-330, 1996.

30. L. D. Borders and S. M. Drury, Comprehensive school counseling programs: a review for policymakers and practitioners, Journal of Counseling and Development, vol. 70, pp. 487-498, 1992.

31. G. L. Landreth, Play therapy: The art of the relationship, Routledge, 2012.

32. M. Liu, G. Huang and X. Zhang, Research progress of child play therapy, Chinese Journal of Clinical Rehabilitation, vol. 8, pp. 2908-2909, 2004

33. D. Ray, S. Bratton, T. Rhine and L. Jones, The effectiveness of play therapy: responding to the critics, International Journal of Play Therapy, vol. 10, pp. 85, 2001.

34. K. Barlow, J. Strother and G. Landreth, Child-centered play therapy: nancy from baldness to curls The School Counselor, vol. 32, pp. 347-356, 1985.

35. K. Barlow, J. Strother and G. Landreth, Sibling group play therapy : an effective alternative with an elective mute child, The School Counselor, vol. 34, pp. 44-50, 1985.

36. A. Dogra and V. Veeraraghavan, A study of psychological intervention of children with aggressive conduct disorder, Indian Journal of Clinical Psychology, vol. 21, pp. 28-32, 1994.

37. G. Hannah, An investigation of play therapy, American Journal of Orthopsychiatry, vol. 25, pp. 601-617, 1986.

38. M. Johnson and T. M. Nelson, Game playing with juvenile delinquents, Simulation \& Games, vol. 9, pp. 461-475, 1978.

39. M. Kaczmarek, A comparison of individual play therapy and play technology in modifying targeted inappropriate behavioral excesses of children, New Mexico State University, 1983.

40. C. E. Schaefer and K. J. O'Connor, Handbook of Play Therapy, Advances and Innovations, John Wiley \& Sons, 1994.

41. M. Burroughs, W. Wagner and J. Johnson,
Treatment with children of divorce : a comparison of two types of therapy, Journal of Divorce \& Remarriage, vol. 27, pp. 83-99, 1997.

42. V. Axline, Nondirective play therapy for poor readers, Journal of Consulting Psychology, vol. 11, pp. 61-69, 1947.

43. E. Alexander, School centered play therapy program, Personnel and Guidance Journal, vol. 43, pp. 256-261, 1964.

44. G. Landreth, Why play therapy, Texas Personal and Guidance Association Guidelines, vol. 21, pp. 1, 1972.

45. G. Landreth, L. Allen and W. Jacquot, A team approach to learning disabilities, Journal of Learning Disabilities, vol. 2, pp. 82-87, 1969.

46. R. Myrick and W. Holdin, A brief report of experience and some opinions, Elementary School Guidance and Counseling Journal, vol. 5, pp. 256-265, 1971.

47. R. Nelson, Elementary school counseling with unstructured play media, Personnel and Guidance Journal, vol. 45, pp. 24-27, 1966.

48. J. Waterland, Actions instead of words: play therapy for the young child, Elementary School Guidance \& Counseling, vol. 4, pp. 180-187, 1970.

49. R. Dawood, Positive psychology in school-based psychological intervention: a study of the evidence-base, The European Journal of Social \& Behavioural Sciences, vol. 5, pp. 954, 2013.

50. M. D. Resnick, P. S. Bearman, R. W. Blum, K. E. Bauman, K. M. Harris, J. Jones, J. Tabor, T. Beuhring, R. E. Sieving, M. Shew, M. Ireland, L. H. Bearinger and J. R. Udry, Protecting adolescents from harm: findings from the national longitudinal study on adolescent health, Jama, vol. 278, pp. 823-832, 1997.

51. M. N. Hegde, Pocket Guide to Assessment in Speech-Language Pathology, San Diego, CA: Singular Publishing Group, 1996.

52. A. Frances, Diagnostic and statistical manual of mental disorders: DSM-IV, American Psychiatric Association, 1994.

53. R. Pierangelo and G. A. Giuliani, EDM: The educator's diagnostic manual of disabilities and disorders, Recording for the Blind \& Dyslexic, 2007.

54. M. R. Folio and R. R. Fewell, Peabody developmental motor scales: Examiner's manual, Pro-ed, 2000.

55. J. Case-Smith, Pediatric occupational therapy and early intervention, 1998.

56. HHS, Child Development Assessment Form, Hong Kong Heep Hong Society, 2006. 